\title{
SIDRE: Symptomatic Improvement of Dry Eye
}

\section{Study}

\section{Clarissa J De Paz Agustin L Gonzalez Chi Ngo}

Eye \& Vision, Richardson, TX, USA

Correspondence: Agustin L Gonzalez 3417 Spectrum Boulevard, Richardson, TX 75082, USA

Email ag@txeyedr.com
This article was published in the following Dove Press journal:

Clinical Optometry

16 March 2017

Number of times this article has been viewed

Purpose: The aim of this study was to evaluate the effectiveness of lifitegrast $5 \%$ ophthalmic solution in reducing the symptoms of eye dryness using Ocular Surface Disease Index (OSDI) questionnaire.

Methods: A single-center study was undertaken to evaluate the clinical outcomes. Fourteen subjects (12 female and 2 male) with symptoms of dry eye and a positive history of recent use of artificial tears were included in the study. OSDI questionnaire scores on the severity of symptoms, visual functionality, and quality of life related to the condition were recorded pre- and post-therapy. Subsequently, score data were analyzed for statistical significance.

Results: The mean age of the 14 subjects was 44.86 (standard deviation [SD] \pm 3.08 ) years, with a range of 23-62 years. Mean duration of the evaluation was 28.79 days with a range of 25-34 days. Baseline OSDI mean score was 49.40 (SD \pm 1.28 ), and post-therapy mean score was 42.26 ( $\mathrm{SD} \pm 0.99$ ). Data analysis revealed that the scores were statistically significantly improved post-lifitegrast therapy in comparison to baseline $(p=0.00041)$.

Conclusion: Lifitegrast $5 \%$ ophthalmic solution may be a beneficial therapeutic option in the management of symptoms associated with dry eye disease.

Keywords: dry eye disease, ocular surface disease, dry eye treatment, lifitegrast

\section{Introduction}

Dry eye disease (DED) symptoms may impair daily activities and quality of life of the affected individuals. ${ }^{1}$ Within the spectrum of DED and related syndromes, symptoms of dry eye may be multifactorial in origin. ${ }^{2}$ Adequate tear physiology and secretion with subsequent mechanical distribution is essential to maintain ocular surface structure and function including optimal vision and comfort. DED affects the tear film functional unit that includes the lacrimal glands, ocular surface, eyelids, meibomian glands, interconnecting neural reflex loop, and corneal surface resulting in discomfort and visual disturbance with objectively measurable physiological changes often associated with damage to ocular surface structure and function. ${ }^{1-3}$

Inflammation plays a prominent role in DED immunophysiology. ${ }^{4}$ The cycle of ocular surface inflammation leading to cell and tissue deterioration is common among all DED classifications. ${ }^{1,4}$ Physiologically, there is an increase in the concentration of cytokines and metalloproteinases at the ocular surface, as well as an increase in osmolarity of the tear film. ${ }^{4}$ These alterations are believed to give rise to subjective complaints associated with the disease. ${ }^{4}$

Various treatment paradigms have been suggested to improve signs or symptoms as our clinical understanding of the pathophysiology and etiology of the ocular surface 
has evolved. ${ }^{5}$ Current professional consensus holds that the interruption of inflammation is the fundamental first step to be taken for preventing further cell and tissue damage and is necessary in successful disease management. ${ }^{1,4,6}$

Contemporary clinical management of DED is directed to stabilize ocular surface bio-integrity and tear film functional unit and prevent further tissue deterioration. A wide range of options including dietary supplementation, tear retention via mechanical procedures such as punctal occlusion, and use of mechanical barriers such as scleral lenses, antibiotics, secretagogues, and even amnion membranes have been suggested as therapies, all primarily guided to managing the progression of tissue degeneration and improvement of symptoms. ${ }^{5,7-11}$ Other common treatment options aimed at promoting improvement of symptoms include tear supplementation using palliative therapies such as lubricant eye drops and medication classes such as nonsteroidal agents, steroids, and immunosuppressants often used concomitantly. ${ }^{12-14}$

Symptoms of dryness are assessed in clinical settings via the use of validated questionnaires that help in quantifying subjective complaints. Validated questionnaires provide a tool useful in monitoring individual's subjective improvements in therapeutic management. The Ocular Surface Disease Index (OSDI) is a validated three-section, 12-item scaled questionnaire evaluating and quantifying severity, visual function, and quality of life related to the symptoms of eye dryness over a 1-week recall period. The OSDI has been recognized as a reliable, valid tool for assessing and quantifying subjective symptoms of DED. ${ }^{15}$

Integrins are transmembrane receptors that mediate cellto-cell interactions believed to play a role in the inflammatory process in DED. ${ }^{16,17}$ The binding of intercellular adhesion molecule-1 (ICAM-1) to lymphocyte function-associated antigen-1 (LFA-1) integrins on the surface of T-cells activates the T-cells with a subsequent initiation of an inflammatory cascade. Lifitegrast is a topically administered, small-molecule LFA-1 antagonist recently approved by the US Food and Drug Administration with a specific indication for the management of signs and symptoms of DED. ${ }^{17-19}$ In clinical studies, lifitegrast has shown some improvement of symptoms of DED patients when compared to placebo. ${ }^{17-19}$

In this clinical study, we evaluated the severity of dry eye symptoms and the associated functions of 14 subjects with DED, prior to and after treatment with lifitegrast 5\% ophthalmic solution. All criteria were quantified and objectively assessed through the use of the OSDI validated questionnaire.

\section{Method}

This study was undertaken in compliance with the Tenets of the Declaration of Helsinki, principles of the EV Research and Ethics Committee (which also approved this study), and Health Insurance Portability and Accountability Act (HIPAA) guidelines. The protocol of the study included obtainment of signed informed consent from the subjects and the assessment of dry eye symptoms via the use of the OSDI questionnaire.

Fourteen subjects were included in the study. Inclusion criteria specified that all patients must be older than 18 years of age, with no history of contact lens use in the last 30 days and an initial presentation with subjective complaints associated with eye dryness. The profile of the subjects based on symptoms and alleviating factors was as follows: symptoms of dryness $(n=14,100 \%)$ and eye irritation $(n=13,93 \%)$ or stinging/burning sensation $(\mathrm{n}=10,71 \%)$, and a positive history of the use of over-the-counter (OTC) drops for the self-directed management of symptom within the last month $(n=14,100 \%)$.

All subjects were instructed to complete the OSDI questionnaire for an initial evaluation of dry eye symptom severity and given a prescription for lifitegrast (Xiidra; Shire Pharmaceuticals, Dublin, Ireland) with instructions to topically apply one drop twice a day to each eye. Subjects were asked to return at day 28 (4 weeks) for evaluation of the therapy. Subjects were not encouraged to but allowed to use their current OTC lubricating drops as needed during this period. Subjects were not prescribed other concomitant therapy and instructed not to use any other medication previously prescribed to address any ocular dryness symptoms during this period. Medications that were not allowed included topical corticosteroids, topical cyclosporine A, oral nutritional supplements, or topical antihistamine either prescribed or obtained OTC. Use of OTC lubricating topical eye drops and gels was allowed as artificial tears can only provide palliative relief of symptoms but not treat inflammation. ${ }^{5}$

At the return visit, subjects were reassessed through the OSDI questionnaire and were also asked to rate their perception of the therapy as positive, neutral, or negative. Pre- and post-lifitegrast OSDI scores were compared using statistical analysis.

\section{Results}

A total of 14 subjects were evaluated in this study. Twelve $(86 \%)$ subjects were female and two (14\%) were male, and the mean age of the subjects was 44.86 (standard deviation [SD] \pm 3.08 ) years, with a range from 23 to 62 years (Table 1). No patient reported or was observed to have undergone punctal occlusion or cauterization of puncta. Three subjects (21\%) had undergone laser in situ keratomileusis (LASIK), and one had a blepharoplasty (7\%), and no subject reported using contact lenses during the last 30 days. All subjects had 
Table I Patient demographics and baseline characteristics $(n=\mid 4)$

\begin{tabular}{ll}
\hline Gender, $\mathrm{n}(\%)$ & \\
$\quad$ Male & $2(14.2)$ \\
Female & $12(85.8)$ \\
Age, mean $\pm S D$ (range) & $44.86 \pm 3.08(23-62)$ \\
Age distribution, years, $\mathrm{n}(\%)$ & \\
$<30$ & $1(7.1)$ \\
$31-45$ & $7(50.0)$ \\
$45-60$ & $5(35.7)$ \\
$>61$ & $1(7.1)$ \\
\hline
\end{tabular}

Abbreviation: SD, standard deviation.

symptoms of dryness ( $\mathrm{n}=14,100 \%)$ and a positive history of recent use of OTC drops for a self-directed management of DED symptom within the last month $(\mathrm{n}=14,100 \%)$.

The mean time interval between the baseline and followup appointment was 28.79 ( $\mathrm{SD} \pm 2.19$, range 25-34) days (Table 2). Baseline symptom severity data collected showed the OSDI questionnaire mean score was 49.40 ( $\mathrm{SD} \pm 1.28$, range 41.67-58.33), while the mean OSDI questionnaire score measured posttreatment was 42.26 ( $\mathrm{SD} \pm 0.99$, range 37.50-47.92) (Table 3). As per the OSDI questionnaire, all subjects were descriptively categorized as having severe DED (OSDI $\geq 33$ ).

Data were analyzed using IBM SPSS Statistics. The results of the paired $t$-test indicated that pretreatment score

Table 2 Time interval (days) between evaluation of pre- and posttreatment OSDI score

\begin{tabular}{ll}
\hline & Time interval (days) \\
\hline Mean $\pm S D$ & $28.79 \pm 2.19$ \\
Range & $25-34$ \\
\hline
\end{tabular}

Abbreviations: OSDI, Ocular Surface Disease Index; SD, standard deviation.

Table 3 Summary of pre- and posttreatment OSDI scores

\begin{tabular}{llllll}
\hline & N & Mean & SD & Minimum & Maximum \\
\hline Pretreatment scores & 14 & 49.40 & 4.79 & 41.67 & 58.33 \\
Posttreatment scores & 14 & 42.26 & 3.69 & 37.50 & 47.92 \\
\hline
\end{tabular}

Abbreviations: OSDI, Ocular Surface Disease Index; SD, standard deviation. was significantly different from the posttreatment score $(p \leq 0001)$. One-way analysis of variance (ANOVA) tests showed there was no difference between the male or female OSDI scores before and after therapy (Table 4). At follow-up visit, subjects were asked about their impression of symptomatic changes and also to rate the therapy on a positive, negative, or neutral scale. Symptom assessment was quantified by OSDI score. Of the 14 subjects evaluated, seven (50\%) reported the therapy to be positive, while seven (50\%) found the therapy to be neutral, but no subject found the therapy to be negative. In addition, no adverse events were reported.

One-way ANOVA tests were performed to find out if there was a statistical difference between the neutral and positive outcome groups. The results indicated that there was no difference between the pretreatment scores for those who had a neutral perception of therapy and those who had a positive perception of treatment. The average pretreatment score for the neutral group was $47.32(\mathrm{SD} \pm 5.06)$ and that for the positive group was 51.94 ( $\mathrm{SD} \pm 3.74$ ). In addition, there was no statistical difference between posttreatment scores for those who had a neutral perception $(p=0.11)$ and those who had a positive perception $(p=0.24)$. The average posttreatment score for the positive group was 43.75 ( $\mathrm{SD} \pm 3.88$ ), while the mean OSDI score for the neutral group was 41.07 ( $\mathrm{SD} \pm 3.34$ ) (Table 5). The results of the paired $t$-test indicated that the mean pretreatment score was significantly different from the posttreatment score for both the positive and the neutral group $(p=0.01$ and $p=0.02$, respectively). Of the three subjects in the LASIK group, two reported positive outcomes, and one reported a neutral outcome; there were no statistically significant differences between the LASIK group and the non-LASIK group $(p=0.12$ ).

Regression analysis was performed to analyze if there was any correlation between the number of days that elapsed from the starting of treatment and the posttreatment score. As the number of days increased, the posttreatment OSDI score decreased by 0.14 points on average; this change was not found to be significant $(p=0.78)$.

Table 4 Pre- and posttreatment scores by gender

\begin{tabular}{lllllll}
\hline Gender & $\mathbf{n}$ & Variable & Mean & SD & Minimum & Maximum \\
\hline F & I2 & Age (years) & 44.00 & 11.95 & 23.00 & 62.00 \\
& & Pretreatment score & 49.31 & 4.89 & 41.67 & 58.33 \\
& Posttreatment score & 41.67 & 3.66 & 37.50 & 47.92 \\
& & Time interval between evaluation (days) & 28.92 & 2.35 & 25.00 & 34.00 \\
M & Age (years) & 50.00 & 9.90 & 43.00 & 57.00 \\
& 2 & Pretreatment score & 50.00 & 5.90 & 45.83 & 54.17 \\
& & Posttreatment score & 45.83 & 0.00 & 45.83 & 45.83 \\
& & Time interval between evaluation (days) & 28.00 & 0.00 & 28.00 & 28.00 \\
\hline
\end{tabular}

Abbreviations: SD, standard deviation; F, female; $M$, male. 
Table 5 Scores by perception of therapy

\begin{tabular}{lllllll}
\hline Perception & $\mathbf{n}$ & Variable & Mean & SD & Minimum & Maximum \\
\hline Neutral & 7 & Age (years) & 46.43 & 13.20 & 23.00 & 58.00 \\
& & Pretreatment score & 47.32 & 5.06 & 41.67 & 56.25 \\
& Posttreatment score & 41.07 & 3.34 & 37.50 & 45.83 \\
& & Time interval between evaluation (days) & 28.86 & 1.35 & 27.00 & 31.00 \\
Positive & & 43.29 & 10.42 & 32.00 & 62.00 \\
& & Age (years) & 51.49 & 3.75 & 47.92 & 58.33 \\
& & Pretreatment score & 43.45 & 3.89 & 39.58 & 47.92 \\
& & Posttreatment score & 28.71 & 2.93 & 25.00 & 34.00 \\
\hline
\end{tabular}

Abbreviation: SD, standard deviation.

\section{Discussion}

DED is a multifactorial disorder affecting a significant percentage of the population in which ocular surface inflammation plays a key role affecting the multiple components of the tear functional unit including nervous pathways, the eyelids, and other elements of the ocular surface..$^{1,6,20}$

There is an inherent challenge in being able to measure subjective improvement of therapy over time. The OSDI questionnaire can quantify symptoms of DED and can assist clinicians as a quick, reliable and valid tool to measure disease state and evaluate therapeutic interventions and outcomes. ${ }^{15}$

Inflammation has been recognized as having a central role in the impairment of the homeostasis of the eye causing symptoms of DED including dryness, foreign body sensation, irritation, itching, light sensibility, destabilized osmolarity of the tear film and signs of subsequent tissue deterioration of the ocular surface. ${ }^{1,3-6}$ The inflammatory component of dry eye is primarily mediated by autoreactive T-cells. ${ }^{4,6,16,18}$ During the process of ocular surface inflammation, cellular surface proteins initiate recruitment and activation of T-cells. ${ }^{4,17-19}$

Cellular signaling molecules (type of cytokines) are upregulated in ocular surface damage. This results from the release of autoantigens upon disruption of ocular surface cells. Cellular signaling molecules stimulate and increase the expression of ICAM-1 on cells. Subsequently, ICAM-1 ligates to LFA-1 integrins on T-cells that have been sensitized by antigen-presenting cells. This ultimately results in T-cell migration and activation. ${ }^{17-20}$ T-cell activation triggers the production of pro-inflammatory cytokines including tumor necrosis factor- $\alpha$ (TNF- $\alpha$ ), interleukins (ILs; IL-1 $\alpha$, IL-1 $\beta$, and IL-6), chemokines, and matrix metalloproteinase-9 and expression of adhesion molecules on the surface of cells. ${ }^{20-22}$

A study on mice model demonstrated a decrease in surface inflammatory infiltrates upon exposure of monoclonal antibodies to ICAM-1/LFA-1 complex. ${ }^{23}$ Improvement in signs of dry eye has been tested with topical anti-VLA-4 on subjects with DED showing both a decreased inflammation and a reduction in the number of T-cells as well as the pro-inflammatory cytokine TNF- $\alpha .{ }^{16}$ Studies have reported that a decreased number of T-cells as well as pro-inflammatory cytokine TNF- $\alpha$ in tissue leads to corneal epithelial repair. ${ }^{16,24}$

Increased levels of ICAM-1 have been identified in the lacrimal and conjunctival tissue of subjects with dry eye. ${ }^{25,26}$ Arguably, interrupting the overexpression of ICAM-1 in the ocular epithelial tissue by decreasing its binding affinity to LFA-1 leads to reduced T-cell activation and migration into tissue which is an effective option to manage the inflammatory component in DED. ${ }^{4}$ In vitro studies have clarified that by inhibiting the formation of the ICAM-1/ LFA-1 complex, it is possible to inhibit T-cell activation in DED. ${ }^{17-19}$

Over the last decade, our knowledge and understanding of DED has expanded, and the role of the inflammatory cycle, CDT4 lymphocytes, cytokines, chemokines, metalloproteinases, and cell-associated immunomodulatory molecules and adhesion molecules involved in the DED process is better understood. ${ }^{4}$ Understanding and recognizing the role of integrins and their interruption of regulation and activation of T-cells by increasing CDT4 lymphocyte migration to the site of inflammation and promoting the production of more pro-inflammatory mediator molecules is an important concept. Understanding the role of the inflammatory cascade molecules involved and the agents used to manage the various steps is crucial in the successful management and use of therapeutic options aimed at treating DED subjects. ${ }^{4}$

Patients suffering from DED experience discomfort and actively seek symptomatic remediation. The newer generation of artificial tears provides better physiological cohesiveness with the tear film which helps to enhance the integrity of the ocular surface but offers no immunotherapeutic value. ${ }^{11,12}$ Ophthalmic topical therapies aimed at managing inflammation have shown multiple hurdles to treatment including slow symptomatic improvements, often requiring concomitant therapy with artificial tears or steroids. ${ }^{13,14,27}$

Measurable positive outcomes obtained with the OSDI questionnaire after lifitegrast treatment for a relatively short 
period are probably associated with the drug's ability to interrupt the formation of ICAM-1/LFA-1 complexes. ${ }^{17-19}$

\section{Conclusion}

Over the last decade, the role of cellular and molecular mediators in the inflammatory cycle and the involvement of adhesion molecule complexes have been better understood. ${ }^{4}$ Palliative therapies such as artificial tears provide limited relief but do not treat the underlying inflammation. ${ }^{28}$ Ophthalmic immunosuppressive treatment that acts by downregulating the expression of inflammatory cytokines provides symptomatic and anti-inflammatory relief but often requires concomitant therapy. ${ }^{14,29,30}$ Topical steroids are useful in managing the inflammation associated with dry eye but remain as a short-term option due to side effects. ${ }^{28}$

Taking into account the various limitations of the study, statistical analysis of the data obtained from the OSDI questionnaire suggests that treatment with lifitegrast $5 \%$ ophthalmic solution can actually improve symptoms associated with DED. The OSDI questionnaire offers a reliable method to obtain values that objectively evaluate and quantify symptoms associated with DED. The statistical significance of these values supports the potential therapeutic benefits of lifitegrast.

The authors recognize and understand the multiple limitations of this study, primarily the small sample size, lack of control subjects, and the utilization of a single site. Notwithstanding, the authors believe that improved posttreatment scores obtained with the OSDI questionnaire reflect the effectiveness of lifitegrast in blocking the ICAM-1/LFA-1 interaction. Furthermore, the analysis of data obtained in this study may set a foundation for the development of larger prospective inferential studies on the potential long-term therapeutic benefits of lifitegrast for treating DED.

\section{Disclosure}

Agustin L Gonzalez is a consultant in Shire Ophthalmics. Clarissa J De Paz and Chi Ngo report no conflicts of interest in this work.

\section{References}

1. Lemp MA, Baudouin C, Baum J, et al. The definition and classification of dry eye disease: report of the Definition and Classification Subcommittee of the International Dry Eye Work Shop. Ocul Surf. 2007;5(2): 75-92.

2. Miljanović B, Dana R, Sullivan DA, Schaumberg DA. Impact of dry eye syndrome on vision-related quality of life. Am J Ophthalmol. 2007; 143(3):409-415.

3. Smith JA, Albeitz J, Begley C, Caffery B, Nichols K, Schaumberg D. The epidemiology of dry eye disease: report of the Epidemiology Subcommittee of the International Dry Eye WorkShop (2007). Ocul Surf. 2007; 5(2):93-107.
4. Stevenson W, Chauhan SK, Dana R. Dry eye disease: an immune-mediated ocular surface disorder. Arch Ophthalmol. 2012;130(1):90-100.

5. Tseng SC. A practical treatment algorithm for managing ocular surface and tear disorders. Cornea. 2011;30 Suppl 1:S8-S14.

6. Gumus K, Cavanagh DH. The role of inflammation and antiinflammation therapies in keratoconjunctivitis sicca. Clin Ophthalmol. 2009;3: 57-67.

7. Shay E, Kheirkhah A, Liang L, Sheha H, Gregory DG, Tseng SC. Amniotic membrane transplantation as a new therapy for the acute ocular manifestations of Stevens-Johnson syndrome and toxic epidermal necrolysis. Surv Ophthalmol. 2009;54(6):686-696.

8. Lemp MA. Management of dry eye disease. Am J Manag Care. 2008;14(3 Suppl):S88-S101.

9. Pflugfelder SC, Solomon A, Stern ME. The diagnosis and management of dry eye: a twenty-five-year review. Cornea. 2000;19(5):644-649.

10. Bavinger JC, DeLoss K, Mian SI. Scleral lens use in dry eye syndrome. Curr Opin Ophthalmol. 2015;26(4):319-324.

11. Galor A, Zheng DD, Arheart KL, et al. Dry eye medication use and expenditures: data from the medical expenditure panel survey 2001 to 2006. Cornea. 2012;31(12):1403-1407.

12. Pflugfelder SC. Prevalence, burden, and pharmacoeconomics of dry eye disease. Am J Manag Care. 2008;14(3 Suppl):S102-S106.

13. Kymionis GD, Bouzoukis DI, Diakonis VF, Siganos C. Treatment of chronic dry eye: focus on cyclosporine. Clin Ophthalmol. 2008;2(4): 829-836.

14. Sheppard JD, Scoper SV, Samudre S. Topical loteprednol pretreatment reduces cyclosporine stinging in chronic dry eye disease $J$ Ocul Pharmacol Ther. 2011;27(1):23-27.

15. Schiffman RM, Christianson MD, Jacobsen G, Hirsch JD, Reis BL. Reliability and validity of the Ocular Surface Disease Index. Arch Ophthalmol. 2000;118(5):615-621.

16. Ecoiffier T, El Annan J, Rashid S, Schaumberg D, Dana R. Modulation of integrin alpha4beta1 (VLA-4) in dry eye disease. Arch Ophthalmol. 2008;126(12):1695-1699.

17. Sheppard JD, Torkildsen GL, Lonsdale JD, et al; OPUS-1 Study Group. Lifitegrast ophthalmic solution $5.0 \%$ for treatment of dry eye disease: results of the OPUS-1 phase 3 study. Ophthalmology. 2014; 121(2):475-483.

18. Murphy CJ, Bentley E, Miller PE, et al. The pharmacologic assessment of a novel lymphocyte function-associated antigen-1 antagonist (SAR 1118) for the treatment of keratoconjunctivitis sicca in dogs. Invest Ophthalmol Vis Sci. 2011;52(6):3174-3180.

19. Semba CP, Torkildsen GL, Lonsdale JD, et al. A phase 2 randomized, double-masked, placebo-controlled study of a novel integrin antagonist (SAR 1118) for the treatment of dry eye. Am J Ophthalmol. 2012;153(6):1050-1060.e1.

20. Brewitt H, Sistani F. Dry eye disease: the scale of the problem. Surv Ophthalmol. 2001;45(Suppl 2):S199-S202.

21. Chotikavanich S, de Paiva CS, Li de Q, et al. Production and activity of matrix metalloproteinase- 9 on the ocular surface increase in dysfunctional tear syndrome. Invest Ophthalmol Vis Sci. 2009;50(7): 3203-3209.

22. Sun Y, Zhang R, Gadek TR, O'Neill CA, Pearlman E. Corneal inflammation is inhibited by the LFA-1 antagonist, lifitegrast (SAR 1118) J Ocul Pharmacol Ther. 2013;29(4):395-402.

23. Edwards JC, Wilkinson LS, Speight P, Isenberg DA. Vascular cell adhesion molecule 1 and alpha 4 and beta 1 integrins in lymphocyte aggregates in Sjögren's syndrome and rheumatoid arthritis. Ann Rheum Dis. 1993;52(11):806-811.

24. Gao J, Morgan G, Tieu D, et al. ICAM-1 expression predisposes ocular tissues to immune-based inflammation in dry eye patients and Sjogrens syndrome-like MRL/lpr mice. Exp Eye Res. 2004;78(4):823-835.

25. Aronni S, Cortes M, Sacchetti M, et al. Upregulation of ICAM-1 expression in the conjunctiva of patients with chronic graft-versus-host disease. Eur J Ophthalmol. 2006;16(1):17-23.

26. Saito I, Terauchi K, Shimuta M, et al. Expression of cell adhesion molecules in the salivary and lacrimal glands of Sjogren's syndrome. J Clin Lab Anal. 1993;7(3):180-187. 
27. Mah F, Milner M, Yiu S, Donnenfeld E, Conway TM, Hollander DA. PERSIST: Physician's Evaluation of Restasis (R) Satisfaction in Second Trial of topical cyclosporine ophthalmic emulsion $0.05 \%$ for dry eye: a retrospective review. Clin Ophthalmol. 2012;6: 1971-1976.

28. Gayton JL. Etiology, prevalence, and treatment of dry eye disease. Clin Ophthalmol. 2009;3:405-412.
29. Sall KN, Cohen SM, Christensen MT, Stein JM. An evaluation of the efficacy of a cyclosporine-based dry eye therapy when used with marketed artificial tears as supportive therapy in dry eye. Eye Contact Lens. 2006;32(1):21-26.

30. Rajpal RK, Digby D, D'Aversa G, Mah F, Hollander DA, Conway T. Intraocular pressure elevations with loteprednol etabonate: a retrospective chart review. J Ocul Pharmacol Ther. 2011;27(3):305-308.

\section{Publish your work in this journal}

Clinical Optometry is an international, peer-reviewed, open access journal publishing original research, basic science, clinical and epidemiologica studies, reviews and evaluations on clinical optometry. All aspects of patient care are addressed within the journal as well as the practice of optometry including economic and business analyses. Basic and clinical Submit your manuscript here: https://www.dovepress.com/clinical-optometry-journal
Dovepress

research papers are published that cover all aspects of optics, refraction and its application to the theory and practice of optometry. The manuscrip management system is completely online and includes a very quick and fair peer-review system, which is all easy to use. Visit http://www.dovepress. com/testimonials.php to read real quotes from published authors. 